\title{
A Clinicopathological Study on the Heart Diseases in the Aged
}

\author{
The Morphological Classification of the 1,000 \\ Consecutive Autopsy Cases
}

\author{
Masaya Sugiura, M.D., Keisuke Hiraoka, M.D., Shinichiro \\ OhKawa, M.D., and Hiroyuki Shimada, M.D.*
}

\section{SUMmary}

Consecutive autopsy of 1,000 cases of the aged disclosed coronary sclerosis in 428 cases, myocardial infarction in 137, cardiac hypertrophy in 237 , valvular heart disease in 120 , conduction disturbances in 96 , cor pulmonale in 41 , pericarditis in 39 , and congenital heart disease or anomalies in 28. There were 343 morphologically normal hearts. A total of 1,022 heart diseases were found in 657 cases, corresponding 1.6 heart diseases per one heart.

Heart diseases in the aged were divided into ( 1 ) those continuing from the younger period and (2) those specifically found in the aged. The latter were non-inflammatory valvular diseases and chronic conduction disturbances.

Mitral regurgitation, including mitral ring dilatation (10), mitral ring calcification (9), spontaneous rupture of the chordae tendineae (2) and calcified aortic stenosis (12) and degenerative aortic regurgitation of prolapsed cusp (35) were produced by various degeneration of the connective tissue of the valves.

A total of 59 cases of conduction disturbances consisted of complete or advanced heart block (15), right bundle branch block (RBBB) (16), RBBB with left axis deviation (17), and left bundle branch block (LBBB) (11). Forty-seven cases showed main lesions in the branching portion of the AV bundle and origin of the bilateral bundle branches, which were closely related to the degeneration of the central fibrous body and fibrosis at the summit of the ventricular septum.

The common field, where the valvular diseases and conduction disturbances occurred, was the fibrous trigone of the heart.

* From the Department of Internal Medicine and Department of Pathology, Tokyo Metropolitan Geriatric Hospital (Yoiku-in) and Department of Clinical Pathology, Tokyo Metropolitan Institute of Gerontology, Sakaccho 35-2, Itabashi, Tokyo, Japan.

The main parts of this study were presented in the Symposium on specificity of the diseases in the aged, at the 14th Annual Meeting of Japan Geriatrics Society on October 17th, 1972.

Received for publication January 24, 1975. 


\section{Additional Indexing Words :}

Aging Degenerative heart disease Geriatric cardiology Valvular disease Conduction disturbance

$7 \mathrm{HE}$ heart diseases in the aged could be classified into 2 main groups; one is the heart diseases starting in the younger age, and the other is the one specifically occurring in the elderly age. ${ }^{1,2)}$ The latter could be closely related to aging processes, and be found especially in the areas where the continuous mechanical stress worked. The purposes of this study were to review various changes and diseases found in the aged heart from the 1,000 consecutive autopsy cases and to classify them in terms of etiology and incidence.

\section{Materials AND Methods}

A total of 1,000 consecutive autopsy material was subjected to this study at Tokyo Metropolitan Geriatric Hospital (Yoiku-in), from January, 1967 to February, 1972. There were 433 men and 567 women. Their age distribution was from 56 to 99 years, with an average of 76 years in men and 80 years in women. Eighty-three \% of cases fell between 70 and 89 years of age (Table I).

Pathological study was done according to the previous study, ${ }^{3)}$ including the heart weight, coronary sclerosis, circumference of the valve rings, thickness of the cusps, thickness and volume of the atria, and ventricles. Cardiac hypertrophy was defined as heart weight more than $350 \mathrm{Gm}^{3)}$ and cardiac atrophy less than 200 $\mathrm{Gm}$. Right ventricular hypertrophy was defined by the thickness of the right ventricular free wall of more than $5 \mathrm{~mm}$. Degree of the coronary stenosis was expressed as count 5 in the complete obstruction, 4 in $75 \%, 3$ in $50 \%, 2$ in $25 \%$, and $I$ in slight stenosis. ${ }^{3), 4)}$ Stenotic index ${ }^{4)}$ was defined as the sum of the highest counts in each of 3 main branches of the coronary arteries. Myocardial infarction was

Table I. Age and Sex of 1,000 Cases

\begin{tabular}{c|r|r|r}
\hline Age & Male & Female & Total \\
\hline $55-59$ & 5 & 0 & 5 \\
$60-64$ & 14 & 7 & 21 \\
$65-69$ & 62 & 32 & 94 \\
$70-74$ & 95 & 77 & 172 \\
$75-79$ & 103 & 126 & 229 \\
$80-84$ & 97 & 183 & 280 \\
$85-89$ & 44 & 102 & 146 \\
$90-$ & 13 & 40 & 53 \\
\hline Total & 433 & 567 & 1,000 \\
\hline Mean Age & 76 & 80 & 78.5 \\
\hline
\end{tabular}


classified in massive and scattered types, and also in large (longer diameter longer than $5 \mathrm{~cm}$ ), middle-sized (between 2 and $5 \mathrm{~cm}$ ), and small (less than $2 \mathrm{~cm}$ ) infarction. Age of the infarction was divided into the fresh, recurrent, progressive, and old infarction. Progressive lesion was defined as a fresh lesion in the peri-infarction region, which was differentiated from the healing processes with fibrosis in the peri-infarction region. Examination of the conduction system was performed according to Lev's method.5) Serial sections of the ventricular septum were stained by hematoxylin and eosin, elastica Van Gieson, periodic acid Schiff, alcian blue, toluidine blue, and Reinhart's colloidal iron method. ${ }^{6)}$

\section{RESULTS}

1. Incidence of heart diseases

Incidence of heart diseases in the aged was shown in the Table II. A total of 343 hearts were found morphologically normal, and a total of 1,022 heart diseases were found in the remaining 657 cases, with an incidence of 1.022 heart diseases per one heart, and 1.6 heart diseases per one diseased heart.

Table II. Incidence of Heart Diseases in the Aged

\begin{tabular}{l|c} 
& (in 1,000 cases) \\
\hline Normal & 343 \\
Coronary Sclerosis & 428 \\
Myocardial Infarction & 137 \\
Hypertrophy & 237 \\
Valvular Heart Disease & 120 \\
Conduction Disturbance & 96 \\
Cor Pulmonale & 41 \\
Pericarditis & 39 \\
Congenital Heart Disease & 28 \\
Aortic Rupture & 11 \\
Others & 22 \\
\hline Heart Diseases & 1,022 \\
Diseased Heart & 657 \\
Heart Diseases per One Heart & 1.6
\end{tabular}

II. Cardiac hypertrophy

Heart weight of a total of 998 cases was shown in Fig. 1. Heart weight between 250 and $300 \mathrm{Gm}$ was the most frequent range in male and female. Cardiac atrophy was found in 88 cases, normal weight in 673 and hypertrophy in 237. Cardiac hypertrophy was due to hypertensive heart disease, except 49 cases of valvular heart disease. 


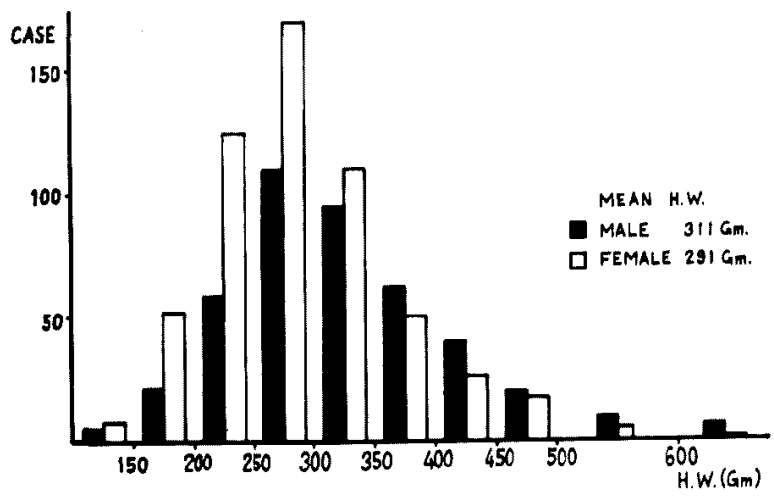

Fig. 1. Heart weight in the aged (998 cases).

CORONARY SCLEROSIS $\bar{C}$ AGING

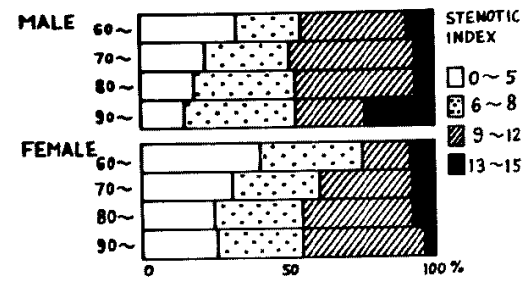

INCIDENCE OF MYOCARDIAL INFARCT

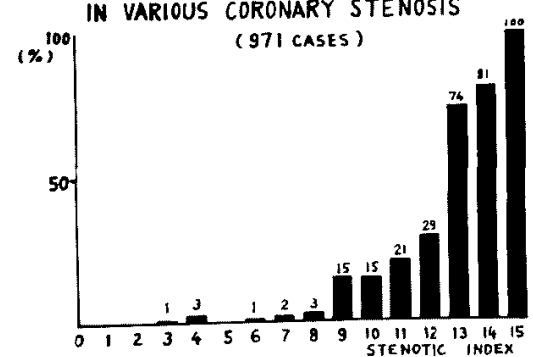

Fig. 2. Coronary sclerosis with aging (upper panel), and the incidence of myocardial infarction in each stenotic indices (lower panel) in 971 aged.

\section{Coronary sclerosis}

Degree of coronary sclerosis producing stenotic lesions was examined in a total of 971 cases. In order to examine the degree of coronary stenosis with aging, 4 groups were made according to the stenotic index; that is group 1 represented hearts with stenotic index of 0 to 5 , group 2 those with stenotic index between 6 and 8, group 3 those between 9 and 12, and group 4 those of 13 to 15 . Fig. 2 showed a tendency of decrease of group 1 with aging ( $p<0.05$ in male, but not significant in female), and increase of group 3 with aging ( $p<0.05$ in female, but N.S. in male). Increase of group 4 in male of 


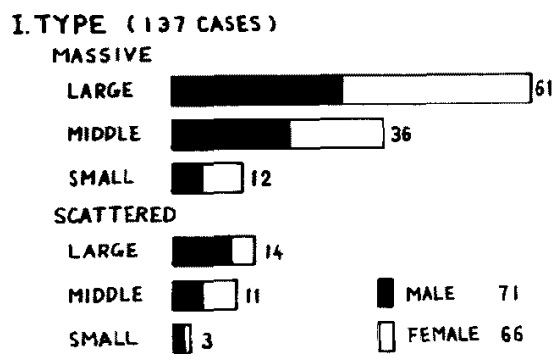

1. AGE OF INFARCT (MASSIVE LARGE)

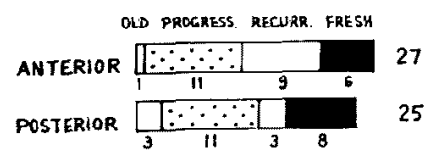

Fig. 3. Types and age of myocardial infarction in the aged (137 cases).

more than 90 years of age was statistically not significant.

Incidence of myocardial infarction in each 16 groups of stenotic index was shown in the lower half of Fig. 2, which indicated an increase of the incidence from index $8(2.9 \%)$ to index $9(14.7 \%)(\mathrm{p}<0.005)$. Also there was marked step-up of the incidence from $29.1 \%$ in index 12 to $74 \%$ in index 13 $(\mathrm{p}<0.005)$. These facts strongly suggested the coronary sclerosis of clinical significance could be defined as index 9 . A total of 428 cases of coronary sclerosis was found with a coronary stenotic index of more than 9 .

IV. Myocardial infarction

A total of 137 cases of myocardial infarction (71 male, 66 female) was found and divided in 61 cases (29 male, 32 female) of massive large myocardial infarction, 36 cases ( 20 male, 16 female) of massive middle-sized infarction, 12 cases ( 5 male, 7 female) of massive small infarction, and 28 cases ( 17 male, 11 female) of scattered infarction, as shown in Fig. 3. Comparison of the age of infarction was made between massive large anterior (27 cases) and posterior (25 cases) infarction, showing a higher incidence of recurrent infarction in the anterior, and a high incidence of progression in both groups. The incidence of cardiac rupture in myocardial infarction was $5.1 \%$ (7 among 137 cases) and $9.8 \%$ among massive large infarction (6 among 61 cases).

V. Valvular heart disease

In Fig. 4, a total of 120 cases of various valvular diseases were classified; 8 cases $(6.7 \%$ ) of rheumatic mitral stenosis, 37 cases $(30.8 \%$ ) of mitral regurgitation, 12 cases $(10 \%)$ of calcified aortic stenosis, 26 cases (21.7\%) of 


\begin{tabular}{|c|c|c|c|c|}
\hline & CASE & $A F$ & $\mathrm{CHF}$ & CARDIAC DEATH \\
\hline$M S$ & \begin{tabular}{ll|}
8 & \\
& $6.7 \%$
\end{tabular} & 75 & $75 \%$ & $75 \%$ \\
\hline$M \quad I$ & $\begin{array}{l}37 \\
30.8 \%\end{array}$ & & & \\
\hline A S & $\begin{array}{l}12 \\
10.0 \%\end{array}$ & & & 25 \\
\hline $\begin{array}{|cc|}\text { A } & \text { I } \\
\text { SYPHILITIC } \\
\end{array}$ & $\begin{array}{l}26 \\
21.7 \% \\
\end{array}$ & & 85 & 69 \\
\hline $\begin{array}{cc}A & 1 \\
\text { DEGENERATIVE }\end{array}$ & $\begin{array}{l}35 \\
29.2 \%\end{array}$ & & & \\
\hline $\begin{array}{ccc}A & S & 1 \\
\text { RHEUMATIC }\end{array}$ & \begin{tabular}{|l|}
2 \\
$1.6 \%$ \\
\end{tabular} & & & \\
\hline TOTAL & 120 & & & \\
\hline
\end{tabular}

Fig. 4. Incidence of various types of valvular diseases and their clinical findings.

Table III. Etiological Classification of Mitral

Regurgitation in the Aged

\begin{tabular}{l|rl}
\hline 1. Ring Dilatation & 10 & $(23.8 \%)$ \\
2. Ring Calcification & 9 & $(21.4 \%)$ \\
3. Nodular Sclerosis & 8 & $(19.1 \%)$ \\
4. Papillary Muscle Dysfunction & 6 & $(14.3 \%)$ \\
5. Rheumatic & 5 & $(11.9 \%)$ \\
6. Rupture of Chordae Tendineae & 3 & $(7.1 \%)$ \\
7. Congenital & 1 & $(2.8 \%)$ \\
\hline & Total & 42
\end{tabular}

syphilitic aortic regurgitation, 35 cases $(29.2 \%)$ of degenerative aortic regurgitation, and 2 cases $(1.6 \%$ ) of rheumatic aortic valvular disease (stenoinsufficiency). The incidence of atrial fibrillation was high $(75 \%)$ in mitral stenosis, and congestive heart failure was frequently found in mitral stenosis and syphilitic aortic regurgitation with an incidence of $75 \%$, and $85 \%$, respectivcly. Death due to cardiac disease was also frequent in these diseases.

Pathological diagnosis of rheumatic mitral valvular disease was made in cases of predominant mitral stenosis and there were no cases of predominant mitral regurgitation. Adding 5 cases of mild mitral regurgitation accompanying with mitral stenosis, there were a total of 42 cases of mitral regurgitation, which were etiologically classified in Table III. A case of chordal rupture had a history of bacterial endocarditis with verruca formation at the end of ruptured chordae, but other 2 cases had no proof of endocarditis and a chorda reaching to the posterior cusp near the posteromedial commissure was ruptured 
with prolapse of the cusp into the left atrium. Histological examination disclosed irregular layers of the connective tissue, and partial loss of elastic fibers.

In 12 cases of calcified aortic stenosis, calcification was localized in the base of the sinus of Valsalva, and/or in the fibrosa layer of the cusps. There were no commissural fusions as found in the rheumatic valvular disease. In 4 cases calcification was based on the congenital bicuspid aortic valve. Aortic regurgitation in the aged were mainly syphilitic ${ }^{7)}$ and degenerative. ${ }^{8)}$ Pathogenesis of the syphilitic orgin was commissural separation with aortic ring dilatation in 11 cases, commissural separation without ring dilatation in 12 . In degenerative aortic regurgitation ring dilatation beyond the physiological ectasia $^{3 \prime}$ was found in only 6 out of 35 cases. Degeneration of the connective tissue of the posterior or right cusps resulted in a prolapse of the cusp. ${ }^{8}$ )

\section{Ghronic cor pulmonale}

A total of 41 cases were diagnosed as chronic cor pulmonale by the right ventricular hypertrophy and/or dilatation, and clinically proved chronic pulmonary diseases, such as pulmonary emphysema in 22 cases, pulmonary tuberculosis in 8, and chronic bronchitis in 5 .

VII. Congenital heart diseases and anomalies

A total of 28 cases of congenital heart diseases and anomalies were found (Table IV). Those, who had congestive heart failure and significant hemo-

Table IV. Congenital Heart Diseases or Anomalies

\begin{tabular}{l|cc}
\hline Ventricular Septal Defect & 4 & 3 \\
Spontaneous closure & & 1 \\
Persistent common A-V canal type & 1 & \\
Patent Ductus Arteriosus & 1 & \\
Partial Hypoplasia of LV & 1 & \\
Partial Hypoplasia of RV & 6 & \\
Isolated Levocardia & 1 & \\
Bicuspid Aortic Valve & 4 & 3 \\
Bicuspid Pulmonic Valve & 9 & 3 \\
Quadricuspid Pulmonic Valve & & 2 \\
Anomaly of Coronary Artery & & 1 \\
Hypoplastic RCA & & \\
Absence of LC & 28 & \\
Abnormal origin & & \\
A-V fistula (closed) & & \\
\hline Total &
\end{tabular}


dynamic effects were a case of patent ductus arteriosus, ${ }^{9)}$ and 4 cases of bicuspid aortic valve with calcified aortic stenosis. Antemortem diagnosis was made in 1 case of ventricular septal defect of Roger type, and a case of levocardia. The other cases were found in autopsy due to clinically silent course; 3 cases of spontaneous closure of ventricular septal defect, 2 cases of hypoplasia of the ventricle, 7 cases of numeral anomaly of the valves, 9 cases of anomaly of the coronary arteries.

VIII. Conduction disturbance

A total of 59 cases were histologically examined among 96 cases of various conduction disturbances, which consisted of 19 cases of $\mathrm{AV}$ block, 64 cases of right bundle branch block (RBBB), and 13 cases of left bundle branch block (LBBB). Fig. 5 showed 15 cases of complete or advanced AV block, 16 cases of RBBB, 17 cases of RBBB with left axis deviation, 11 cases of LBBB. Main lesions were at the branching portion of the AV bundle and/or origin of the bilateral bundle branches. Only 2 cases had main lesions at the AV node and penetrating portion of the AV bundle. In 10 cases main lesions were at the distal portion of the bilateral bundle branches. Characteristic findings at the bifurcation were (1) degeneration of the central fibrous body, and (2) summit fibrosis of the ventricular septum, which induced fibrosis of the branching portion of the $\mathrm{AV}$ bundle and the bilateral bundle branches. Also there was local increase of the acid mucopolysaccharides.

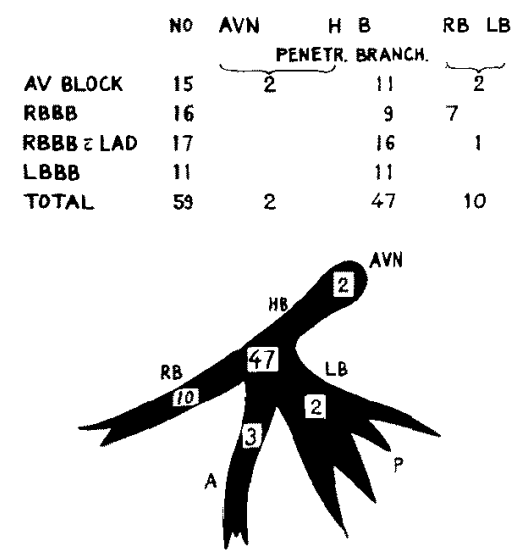

Fig. 5. Sites of principal lesions in various conduction disturbances. Abbreviations: AVN; atrioventricular node, HB; bundle of $H$ is, PENETR.; penetrating portion of the bundle of His, BRANCH.; branching portion of the bundle of His, RB; right bundle branch, I.B; left bundle branch, A; left anterior fascicles, $P$; left posterior fascicles. 


\section{Discussion}

Examination of the incidence of various types of heart diseases in a large series was found in few reviews. Wartman and Hellerstein ${ }^{10}$ examined incidence of heart diseases in 2,000 consecutive autopsy cases, which included all age groups with mainly people of 40 and 69 years of age. They stated the incidence was $49.2 \%$ (984 cases) and main disease groups were rheumatic, hypertensive and coronary heart disease. Froment et al ${ }^{11)}$ found 1,230 heart diseases in 1,000 adult autopsy cases more than 19 years old with a ratio of 1.23. Pemerance ${ }^{12)}$ studied 370 hearts dying over the age of 75 and $65 \%$ of cases showed multiple etiologies. In our study 1,022 heart diseases were found in 657 cases with a ratio of 1.6. This high incidence could be explained by the aged group in this study. Among 162 cases with cardiac failure, ${ }^{12)}$ ischemic heart disease was the commonest $(48.5 \%)$, followed by degenerative calcific changes in mitral ring or aortic cusp (45\%), hypertension $(35 \%)$, senile cardiac amyloidosis $(18 \%)$, endocarditis (3\%), mucoid degeneration of the mitral valve $(6 \%)$, and syphilis $(2 \%)$. In our study amyloidosis was extremely rare.

Heart weight of $350 \mathrm{Gm}$ was considered as the normal upper limit according to the previous study on the normality of the aged heart. ${ }^{3}$. Distribution of the heart weight was quite similar to that shown by McKeown, ${ }^{13}$ ) except that the peak weight in the latter was heavier $(300$ to $350 \mathrm{Gm})$ than our result (250 to $300 \mathrm{Gm}$ ).

Coronary arteries of the stenotic index less than 5 were evaluated as almost normal as previously shown. ${ }^{3}$ ' But the incidence of myocardial infarction by stenotic index indicated stenotic index 9 as clinically significant coronary sclerosis in Fig. 2. Index of 6 to 8 were considered to be borderline. About a half of cases (428 cases) was diagnosed as coronary sclerosis from the morphological standpoint.

Bedford and Caird"14) proposed "isolated aortic regurgitation" for the one in the aged, and considered senile ectasia of the aortic ring as its pathogenesis. The authors could not find aortic ring dilatation as a unitary cause of regurgitation, and proposed the weakened collagen fibres of the aortic cusps by various types of degeneration as a pathogenesis of this type of aortic regurgitation. ${ }^{8)}$ As a pathogenesis of the calcified aortic stenosis, degeneration of the valve fibrosa ${ }^{15}$ and partly congenital bicuspid aortic valve ${ }^{16)}$ were the most plausible mechanisms. Among a total of 67 cases of mitral ring calcification, 9 cases were diagnosed as mitral regurgitation. Spontaneous rupture of the chordae tendineae was reported in a high incidence in the aged. ${ }^{17}$ Disruption of the laminal layers and loss of the elastic fibers found 
in our 2 cases were considered the same degenerative processes of the connective tissue. ${ }^{181}$

Our previous study showed a high incidence of left axis deviation in the aged, $\left.{ }^{19}\right)$ and a higher incidence of left axis deviation associated with $\mathrm{RBBB}$ in the aged. ${ }^{20)}$ Histological examinations showed main lesions at the bifurcation of the common AV bundle with right bundle branch and antcrior fascicles of the left bundle branch. ${ }^{6}$ ) Association of RBBB with right axis deviation was shown to be related to the lesions of right bundle branch and the posterior fascicles of the left bundle branch. ${ }^{21}$ ) These changes were already described by Lenégre, ${ }^{22)}$ Lev, ${ }^{23)}$ and Davies ${ }^{24 \prime}$ and closely related to the trifascicular block. ${ }^{25)}$ These changes were not related to the ischemia, inflammation and metabolic disorders. The characteristics of this group of conduction disturbances were (1) marked degeneration of the central fibrous body and local accumulation of the acid mucopolysaccharides, (2) fibrosis of the septal summit which was localized and not related to the vascular changes, and (3) degeneration or fibrosis of the conduction system was mainly localized between these 2 types of lesions, suggesting a common specific mechanism in old age. ${ }^{26)}$

Heart diseases in a total of 1,000 aged cases were classified etiologically in Table V. The first group of heart diseases which continued from younger age were (1) congenital heart disease, (2) hypertensive heart disease, (3) coronary heart disease, (4) rheumatic valvular disease, (5) syphilitic aortic regurgitation, (6) mitral regurgitation including papillary muscle dysfunction,

Table V. Heart Diseases in Old Age

I. Heart Diseases from Younger Age

1. Congenital H.D.

2. Hypertensive H.D.

3. Ischemic H.D.

4. Rheumatic Valvular D.

5. Syphilitic Aortic Regurgitation

6. Mitral Regurgitation

Papillary muscle dysfunction

Ruptured chordae tendineae (due to endocarditis)

7. Cor Pulmonale

8. Conduction Disturbance (inflammatory, ischemic)

II. Heart Diseases Specific for Aged

1. Mitral Regurgitation

Ring calcification

Ring dilatation

Ruptured chordae tendineae (due to degeneration)

Nodular sclerosis

2. Calcified Aortic Stenosis

3. Degenerative Aortic Regurgitation

4. Conduction Disturbance (chronic) 
rupture of chordae tendineae due to endocarditis, (7) chronic cor pulmonale, and (8) conduction disturbances in acute myocardial infarction. On the other hand, the second group of heart diseases which were considered to be specific in the aged, were (1) mitral regurgitation including ring calcification, ring dilatation, spontaneous chordal rupture and nodular sclerosis, (2) calcified aortic stenosis, (3) degenerative aortic regurgitation, and (4) chronic conduction disturbances.

The 2nd group of heart diseases, specific in the aged could be summarized as the degenerative heart disease, which induced specific forms of valvular diseases and conduction disturbances by degeneration of the connective tissues of the heart.

\section{AckNoWledgement}

The authors greatly appreciate the expert technical assistance of Miss Ayako Toku.

\section{REFERENCES}

1. Sugiura M, Ueda $K$ : On the specificity of heart diseases in the aged. Jap J Geriat 10: 73,1973 (in Japanese)

2. Harris R: The management of geriatric cardiovascular disease. J B Lippincott Co, Philadelphia, p 215, 1970

3. Sugiura $\mathrm{M}$ et al: Clinicopathological studies on normality in the aged heart. Jap J Geriat 6: 297,1969 (in Japanese)

4. Sugiura M, Okada R: A clinicopathological study on the natural history of myocardial infarction in the aged. Jap Circulat J 36: 1, 1972

5. Lev M, Widran J, Erickson EE: A method for the histopathologic study of the atrioventricular node, bundle and branches. Arch Path 52: 73, 1951

6. Sugiura M, Okada R, Hiraoka K, Ohkawa S: Histological studies on the conduction system in 14 cases of right bundle branch block associated with left axis deviation. Jap Heart J 10: 121,1969

7. Hiraoka K, Ohkawa S, Sugiura M: A clinicopathological study on the syphilitic aortic regurgitation in the aged. Jap Heart $\mathrm{J}$ 14: 22, 1973

8. Sugiura M, Okada R, Hiraoka K, Ohkawa S, Shimada H: A new etiological concept of the aortic regurgitation in the aged. Prolapsed cusp due to degeneration. Jap Heart J 10: 20, 1969

9. Ohkawa S, Hiraoka K, Shimada $\mathbf{H}$, Sugiura $\mathbf{M}$ : A case of patent ductus arteriosus in a $74-$ year-old woman. Jap Heart J 12: 500, 1971

10. Wartman WB, Hellerstein HK: The incidence of heart disease in 2,000 consecutive autopsies. Ann Int Med 28: 41, 1948

11. Froment R, Plauchu G, Perrin A, Normand J: La mortalité cardioaortique de l'adulte et les cardiopathies de causes multiples (d'aprés 1,000 autopsies consécutives). Arch mal coeur 59: 190,1966

12. Pomerance A: Pathology of the heart with and without cardiac failure in the aged. Brit Heart J 27: 697, 1965

13. McKeown F: Pathology of the aged. Butterworths, London, 1965 
14. Bedford PD, Caird FI: Valvular disease of the heart in old age. J \& A Churchill, Ltd, London, 1960

15. Shapiro JH, Jacobson HG, Rubinstein BM, Poppel MH, Schwedel JB: Calcifications of the heart. CC: Thomas, Ill, 1963

16. Roberts WC: Anatomically isolated aortic valvular disease. The cause against its being of rheumatic etiology. Am J Med 49: 151, 1970

17. Acar J, Caramanian M, Perrault M, Luxereau P, Arnaud J C: Les insuffisances mitrales par ruptures de cordages d'origine dégénérative. Arch mal ccuur 61 : 1724, 1968

18. Ueno $K$, Iizuka $H$, Ohkawa $S$, Sugiura $M$ : Two aged cases of mitral insufficiency due to spontaneous rupture of chordae tendineae. Jap Heart J 13: 457, 1972

19. Sugiura M, Okada R, Iizuka T, Kubo F, Hiraoka K, Ohkawa S: A consideration on the left axis deviation, with special reference to right bundle branch block associated with left axis deviation as bilateral bundle branch block. Saishin-Igaku 23: 1460, 1968 (in Japanese)

20. Sugiura M, Hiraoka K, Ohkawa S: An electrocardiographic study on the electrical axis of right bundle branch block in the aged. Jap Heart J 14: 510, 1973

21. Sugiura M, Hiraoka K, Ohkawa S: A histological study on the conduction system in 16 cases of right bundle branch block associated with right axis deviation. Jap Heari J 15: 113, 1974

22. Lenégre J: Contribution à l'étude des blocs de branche. JB Baillière et fils, Paris, 1958

23. Lev M: Anatomic basis for atrioventricular block. Am J Med 37: 742, 1964

24. Davies MJ: Pathology of conducting tissue of the heart. Butterworths, London, 1971

25. Rosenbaum MB, Elizari MV, Lazzari JO: The hemiblocks. Tampa Tracings, Oldsmar, Florida, 1970

26. Sugiura M, Ohkawa S, Okada R: Aging of the central fibrous body with special reference to the conduction disturbance. Proc 8th Internat Congr Gerontol 2: 23, 1969 